Review paper

\title{
External beam radiation therapy with kilovoltage $\mathrm{x}$-rays
}

\author{
Dylan Y Breitkreutz ${ }^{\text {a }}$, Michael D Weil ${ }^{\mathrm{b}}$, Magdalena Bazalova-Carter ${ }^{\mathrm{c}, *}$ \\ ${ }^{a}$ Department of Radiation Oncology, Stanford University, Palo Alto, CA, USA \\ ${ }^{\mathrm{b}}$ Sirius Medicine LLC, Half Moon Bay, CA, USA \\ ${ }^{\mathrm{c}}$ Department of Physics and Astronomy, University of Victoria, Victoria, BC, Canada
}

\section{A R T I C L E I N F O}

\section{Keywords:}

Radiotherapy

Kilovoltage x-rays

Microbeam therapy

FLASH

\begin{abstract}
A B S T R A C T
Kilovoltage $(\mathrm{kV})$ x-rays are most commonly used for diagnostic imaging due to their sensitivity to tissue composition. In radiation therapy (RT), due to their fast attenuation, kV x-rays are typically only used for superficial irradiation of skin cancer and for intra-operative RT (IORT). Recently, however, a number of $\mathrm{kV}$ RT techniques have emerged. In this review article, we provide a brief overview of the use of $\mathrm{kV}$ x-rays for RT.

Various kV x-ray source technologies suitable for RT, such as conventional x-ray tubes as well as novel x-ray sources, are first described. This x-ray source section is then followed by a section on their implementation in terms of clinical, veterinary and preclinical applications. Specifically, IORT, superficial RT and dose enhancement with iodine and gold nanoparticles, as well as microbeam RT and FLASH RT are discussed in this context. Then, a number of kV x-ray RT applications in modeling and proof-of-principle stages, such as breast external beam RT with rotational sources, kilovoltage arc therapy and the BriXS Compton pulsed x-ray sources, are reviewed. Finally, some clinical and economic considerations for the development of kV RT techniques are discussed.
\end{abstract}

\section{Introduction}

\subsection{History of kilovoltage $x$-ray beam radiotherapy}

Wilhelm Roentgen discovered $\mathrm{x}$-rays in 1895 . Within months of the discovery, $\mathrm{x}$-rays were being applied to medical problems, primarily for imaging. The first radiation treatment of cancer using x-rays was recorded in 1896 when Victor Despeignes treated a patient with stomach cancer. Despite this first application of x-rays for stomach cancer, the primary therapeutic use of $\mathrm{x}$-rays in these early days was only for superficial lesions. Early x-ray tube technology was only capable of generating $\mathrm{x}$-rays in the kilovoltage $(\mathrm{kV})$ energy range and the treatment of deep-seated lesions was limited by radiation-induced skin damage. In 1909, Alban Kohler, in an attempt to reduce the skin toxicity of kV x-rays and enable their use for the treatment of deep-seated lesions, devised the method of grid therapy [1]. By passing the x-rays through a metal grid, the dose to skin was spatially fractionated thereby reducing the magnitude of skin toxicity. The basic technology of the $\mathrm{x}$-ray tube remained relatively unchanged in the century following the discovery of $\mathrm{x}$-rays.

Today, 20-150 kVp x-rays are primarily used for diagnostic imaging.
Higher-energy 100-500 kVp x-rays are used for superficial therapy, and in some cases, intraoperative radiation therapy. In this review article, we will summarize applications of $\mathrm{kV}$ radiotherapy with $\mathrm{x}$-rays of energies between 50 and $320 \mathrm{kVp}$, typically referred to as superficial and orthovoltage $\mathrm{x}$-rays. While the most common clinical applications of $\mathrm{kV}$ $\mathrm{x}$-rays to superficial RT and intraoperative RT are briefly mentioned, this review focuses on 'exotic' applications of $\mathrm{kV}$ x-rays designed to treat deep-seated tumors either by combining kilovoltage RT with either contrast material injection or by designing non-standard x-ray sources. Various applications of kV RT, mostly in the treatment planning stage but also in pre-clinical or clinical trials are summarized here.

\subsection{Why use $k V$ radiotherapy?}

Medical applications of x-ray beams in RT have been strictly segmented according to the energy employed by the radiation machines. High-energy (megavoltage, MV) systems are used for cancer therapy because their beams spare the skin and readily penetrate tissue. On the other hand, low-energy $\mathrm{kV}$ devices are mainly used for imaging, e.g. in computed tomography (CT), mammography and chest/bone x-ray imaging. These $\mathrm{kV}$ x-ray beams are more sensitive to tissue composition

\footnotetext{
* Corresponding author.

E-mail address: bazalova@uvic.ca (M. Bazalova-Carter).
} 
and less penetrating and their use for treatment is conventionally limited to skin cancer. While it is challenging to treat deep-seated tumors with $\mathrm{kV}$ x-rays, benefits of radiation treatment with $\mathrm{kV}$ x-rays exist.

First, the generation of $\mathrm{kV} \mathrm{x}$-rays (see section 2) is much less complex than generation of MV x-rays. Conventional MV linear accelerators (linacs) used for clinical MV RT are sophisticated in their design and contain many components including an accelerating waveguide with a high manufacturing cost. The power and space requirements for operating linacs are greater than for operating $\mathrm{kV}$ x-ray devices. In addition, linacs require housing with 2-meter thick concrete walls to protect personnel; $\mathrm{kV}$ x-ray units only require $\sim 2$-millimeter lead shielding. In light of the considerable cost reduction possible with $\mathrm{kV}$ RT, it could become a suitable cancer treatment modality in the limited-resource settings of developing countries.

Despite advancing healthcare technology, world-wide annual cancer mortality exceeds deaths from HIV-AIDS, tuberculosis and malaria combined. In part, this is the result of a significant and disturbing inequality in global delivery of cancer treatment; $70 \%$ of new cases are in the developing world where cases go undiagnosed and untreated because of cost [2].

$\mathrm{X}$-ray treatment is effective as a single or combined modality for local-regional tumor control. It is also one of the most precisely planned and delivered therapeutic options. MV linacs and the infrastructure needed for treatment cost $\sim$ US\$5M and carry significant operating expenses in terms of personnel, supporting devices and services. The unit's housing, requiring concrete bunkers, costs $\sim \$ 1.5 \mathrm{M}$ to build. There has been little challenge to the present strategy restricting MV linear accelerators to treat most cancers, while consigning $\mathrm{kV}$ x-rays to imaging. Though $\mathrm{kV}$ x-ray systems have not been optimal for therapy within the body, they offer the potential for simultaneous high-quality imaging during treatment and are undoubtedly much less costly than MV systems.

\section{X-ray beam generation}

\subsection{Conventional $x$-ray tubes}

The technology currently used to produce $\mathrm{kV}$ x-rays has not fundamentally changed from the original vacuum tube design used in Roentgen's experiments. An x-ray tube consists of an evacuated glass tube containing an anode and a cathode. High voltage is applied across the vacuum tube and thermionic emission is used to liberate electrons from the cathode. The electrons are accelerated across the tube and strike the anode. The anode is made of a high atomic number $(Z)$ metal and the rapid deceleration of the electrons incident on the anode produces photons by bremsstrahlung radiation. Anode design varies among $\mathrm{x}$-ray tubes based on their application. X-ray tubes used for imaging employ a rotating anode which allows for smaller electron focal spots with high instantaneous current without exceeding the heat load specifications of the anode. X-ray tubes for therapy use larger electron focal spots along with lower currents over longer periods and use a large stationary anode [3].

X-ray tube potential and added filtration are the main factors affecting the beam quality typically quoted in either mean energy or the half-value layer (HVL). For radiation therapy of deep-seated tumors, more filtration with higher tube potential, resulting in higher beam energy associated with deeper tissue penetration, is typically desirable. However, higher beam energy results in more heat-loading of the anode that can lead to anode melting. In addition, increased beam filtration decreases x-ray output, which in turn increases treatment time. A compromise between $x$-ray beam energy and beam filtration has to be identified for each radiotherapy application.

\subsection{Novel technology}

Apart from conventional x-ray tubes, a number of other x-ray sources that could be considered for the delivery of radiotherapy have been developed and will be discussed here.

\subsubsection{Scanning electron sources}

Since electrons are light charged particles, they can be easily steered electromagnetically with magnetic fields on the order of only 10-20 Gauss. There are two existing examples of diagnostic x-ray sources generated by scanned electron beam: the electron-beam computed tomography (EBCT) system [4] and the scanning beam digital x-ray (SBDX) source. A modified design of the SBDX system has been simulated for the delivery of kilovoltage x-ray beam arc therapy (KVAT) discussed in section 3.4.2.

The SBDX source consists of a large $(23 \times 23) \mathrm{cm}^{2}$ tungsten anode and an electron beam scanning the anode in an array of $100 \times 100$ spots. The resulting x-ray beams from the transmission target are then shaped into $1.5-\mathrm{mm}$ diameter beamlets directed towards the $(5.5 \times 5.5)$ $\mathrm{cm}^{2}$ detector by an $\sim 2$-cm-thick brass collimator [5]. The source was designed for the use in interventional and diagnostic radiography with lower radiation exposure to an interventionalist [6].

\subsubsection{Miniature $x$-ray tubes}

Small-size x-ray sources can be conveniently used for interstitial treatment of tumors in intraoperative treatments or for brachytherapy. In 1996, a novel miniature x-ray tube, the primary component of a Photon Radiosurgery System (PRS), was presented [7]. The electron gun was a conventional miniature gun with a barium oxide thermoionic cathode. Three anodes were used to extract, focus and accelerate the electron beam that impinged on a gold target to produce x-rays. The portable low-power 3-mm diameter $100-\mathrm{mm}$ long x-ray source was capable of operating at $40 \mathrm{kV}$ tube voltage and $40 \mu \mathrm{A}$ tube current generating a beam with mean energy of $16 \mathrm{keV}$.

The more commonly used miniature Xoft Axxent x-ray tube consists of a disposable microminiature $\mathrm{x}$-ray tube with a $<1$-mm anode integrated into a cooled, flexible, disposable sheath of $5.3 \mathrm{~mm}$ in diameter. The Axxent x-ray source operates at tube voltages of 20 to $50 \mathrm{kV}$ and tube currents of $1-300 \mu \mathrm{A}$ producing air kerma strength of up to 1600 $\mathrm{Gy} . \mathrm{cm}^{2} \cdot \mathrm{h}^{-1}$ and it is designed for a lifetime of $2.5 \mathrm{~h}$ [8]. Another commercial system which uses a small form $(7 \mathrm{~cm} \times 11 \mathrm{~cm} \times 17 \mathrm{~cm})$ x-ray tube is the INTRABEAM (Carl Zeiss Surgical, Oberkochen, Germany) intraoperative radiotherapy system. This system is capable of using various applicators which are inserted directly inside the surgical cavity which is then irradiated with $50 \mathrm{kV}$ photons [62].

\subsubsection{Carbon nanotubes}

In most commercial x-ray sources, the properties of the electrons striking an anode drive many of the properties of the resulting $x$-ray beam, such as its spatial and temporal distribution. Conventional x-ray sources take advantage of thermionic emission (TE) for the generation of the electron beam, which poses challenges in terms of temporal (long beam ramp-up and cool-down times, up to $\sim 1 \mathrm{~s}$ ) and spatial (large $\sim 1$ $\mathrm{mm}$ beam size) $\mathrm{x}$-ray beam characteristics. However, in field emission (FE), electrons tunnel through the narrowed potential barrier caused by an application of a high electric field. As a result, a very fast x-ray emission with response times on the order of $50 \mu$ s can be achieved [9]. In addition, due to the high-spatial resolution fabrication of carbon nanotubes (CNTs), FE-based CNT x-ray sources of $5 \mu \mathrm{m}$ in size have been manufactured [10].

CNTs x-ray sources have been designed with imaging tasks in mind. They are typically capable of producing microfocus $\mathrm{x}$-ray beams with anode voltages up to $70 \mathrm{kV}$, albeit with typically low $\sim \mathrm{mA}$ currents [11]. Thanks to their small focal spot on the order of $\mu \mathrm{m}, \mathrm{CNT}$ s have been studied for the use in spatially-fractionated microbeam radiotherapy (MRT) discussed in section 3.3.2.

A miniaturized CNT has been developed by KAIST University in Korea for the use in intra-cavitary radiotherapy [12]. The 7-mm diameter 47-mm long x-ray tube operates at tube voltages of up to $60 \mathrm{kV}$ 
producing dose rates of $100 \mathrm{~Gy} / \mathrm{min}$ in permanent operation. The advantage of a CNT-based miniature $\mathrm{x}$-ray tube compared to conventional miniature $\mathrm{x}$-ray tubes described in section 2.2.2 is their longer lifetime and cold emission radiation not requiring additional cooling.

\subsubsection{Synchrotron sources}

When electrons are accelerated on a curved path, they lose some of their energy by emission of $\mathrm{x}$-rays termed synchrotron radiation. Synchrotron radiation is typically extracted in bending magnets of $\mathrm{a} \sim \mathrm{GeV}$ electron beam circulating in a storage ring. Similar to x-ray tube beams, synchrotron radiation has a broad energy spectrum, but it is distinctive in a number of aspects compared to x-ray sources featuring an electron beam striking an anode. Synchrotron x-ray beams are of high flux, high brilliance, pulsed with short $\sim$ picosecond-long pulses and polarized.

Three synchrotron beamlines were used in radiation therapy experiments discussed in this article: the ID17 beamline at the European Synchrotron Research Facility (ESRF), the x17B beamline at Brookhaven National Laboratory (BNL) and the Imaging and Medical Beamline (IMBL) at the Australian Synchrotron. All beamlines are similar in their beam characteristics and only the ID17 ESRF beamline, with the most RT publications, will be briefly described. The high-brilliance lowdivergence ID17 $\mathrm{x}$-ray beam of $1-3 \mathrm{~mm}$ in height and $\sim 40 \mathrm{~mm}$ in width can deliver dose rates of 8,000 to $16,000 \mathrm{~Gy} / \mathrm{s}[13,14]$. The $\mathrm{x}$-ray beam contains 30-600 keV x-rays with a mean energy of $\sim 105 \mathrm{keV}$ [15].

\subsubsection{Compton sources}

Compton x-ray sources work on the principle of inverse Compton scattering (ICS). In 1998, Huang and Ruth proposed a compact laserelectron storage ring (LESR) for electron beam cooling or x-ray generation [16]. When a laser beam interacted with an electron bunch, a highbrilliance x-ray beam is generated. In the LESR source operated in transient mode, a 2-J power laser with 3-mm long pulses is scattered off $100 \mathrm{MeV}$ electron bunches with $1.3 \times 10^{10}$ electrons and a $200 \mathrm{keV}$ photon beam is generated with a flux of $2.6 \times 10^{20}$ photons/s. A commercial example of such a source, the Compact Light Source (CLS) manufactured by Lyncean Technologies Inc, was operated at $13.5 \mathrm{keV}$ with $3 \%$ energy spread to image a moth placed at $10 \mathrm{~m}$ from the $\mathrm{x}$-ray source using phase-contrast $\mathrm{x}$-ray imaging [17]. The BriXs (Bright and compact X-ray Source), used for an RT study presented in section 3.4.3, is a twin Compton $\mathrm{x}$-ray source. The operation of the BriXS source is based on superconductive cavities technology for the electron beam with energy recirculation and on a laser system in Fabry-Pérot cavity at a repetition rate of $100 \mathrm{MHz}$, producing 20-180 keV x-ray beam [18].

\section{Applications of $\mathrm{kV}$ radiotherapy}

\subsection{Clinical applications}

\subsubsection{Intraoperative radiotherapy}

Intraoperative radiotherapy (IORT) is a method by which a large dose of radiation is delivered directly to the tumor site. This technique is possible due to direct access to the tumor site during a surgical procedure. Since there is no overlying tissue during IORT, and therefore no need for skin-sparing, $\mathrm{kV}$ x-rays are preferred over higher energy photons due to their reduced penetration, which reduces dose to normal tissues beyond the tumor site. IORT was first introduced in the $1960 \mathrm{~s}$ and consisted primarily of x-ray tube systems installed in surgery suites [19]. While not a common method of radiotherapy, due to the surgical requirements, the ability to deliver a large dose directly to the tumor site, as well as the potential for physically spacing surrounding normal tissue from the irradiated area, results in an enhanced therapeutic ratio. However, the increased attenuation of the $\mathrm{kV} x$-rays in bone due to a higher photoelectric cross-section is a disadvantage. Alternatives to $\mathrm{kV}$ $\mathrm{x}$-ray IORT include $\mathrm{MeV}$ electron therapy, which has the advantage of reduced dose past the tumor site in comparison to $\mathrm{kV} \mathrm{x}$-rays. In recent years, advances in technology have resulted in mobile $\mathrm{kV}$ x-ray IORT platforms which can provide advanced beam shaping and require less room shielding.

One novel technology which is well suited to IORT is the miniature $\mathrm{x}$ ray tube. The small size of miniature $\mathrm{x}$-ray tubes allows them to be placed directly within a patient and directly at the site requiring irradiation. The Xoft Axxent miniature $\mathrm{x}$-ray tube has been extensively used for intraoperative treatment of early stage breast cancer [20]. CNTbased miniature $\mathrm{x}$-ray tubes in combination with endoscopic interventional technology have also been considered to treat the oral cavity and larynx [21,22]. IORT technology is an expansive field and dedicated reviews on IORT exist and should be consulted by the reader for further information [19].

\subsubsection{Superficial radiotherapy}

Kilovoltage x-rays are also used for treatment of superficial cancers [23]. The energy spectrum of $x$-rays for this application ranges from 50 to $150 \mathrm{kVp}$. Since the cancer is superficial, skin-sparing is not generally a restrictive concern in these treatments. Due to the capability of many linacs to generate $\mathrm{MeV}$ electrons, it is common for superficial cancers to be treated with $\mathrm{MeV}$ electrons rather than $\mathrm{kV}$ x-rays which would require additional technology. Further reasons for the use of $\mathrm{MeV}$ electrons over $\mathrm{kV}$ x-rays are the finite range of electrons, higher dose rates and ease of modelling in modern treatment planning systems.

\subsubsection{Dose enhancement with iodine}

Due to the increased probability of photo-electric interactions, $\mathrm{kV} \mathrm{x}$ ray beams have the potential to increase radiation dose to a target loaded with $\mathrm{x}$-ray contrast agents of high atomic number $(Z)$, such as iodine. The increased photo-electric effect occurring in the high- $\mathrm{Z}$ material results in the emission of short-range Meitner electrons, more commonly referred to as Auger-electrons first discovered by Lise Meitner in 1922 [24]. Such electrons deposit their energy locally in the vicinity of the high- $\mathrm{Z}$ material and damage cells loaded with the contrast agent, causing the so-called "radiosensitization."

In 1999, two publications investigating the treatment of brain tumors with a modified CT scanner were published $[25,26]$. Termed CTRx, the CT scanner with a modified pencil-beam collimator was able to function as both a diagnostic and therapeutic system. Mesa et al. used Monte Carlo dose calculations to investigate the dosimetric properties of the CTRx system when used to treat brain tumors injected with iodine contrast for tumor dose enhancement. The energy spectrum used in the simulations was taken from the $140 \mathrm{kVp}$ setting of a GE CT scanner. Skull dose reduction was explored both by means of increasing the concentration of iodine (up to $20 \mathrm{mg} / \mathrm{ml}$ ) in the tumor as well as the use of three non-coplanar $\left(20^{\circ}, 0^{\circ}\right.$ and $\left.-20^{\circ}\right)$ treatment arcs by tilting the gantry. The CTRx treatments were compared to simulated treatments with $10 \mathrm{MV}$ photons. The primary factor in achieving desired dose distributions within the tumor, as well as skull dose reduction, was found to be the concentration of iodine. Higher concentrations resulted in more tumor dose and less skull dose. The highest skull dose was $80 \%$ of the maximum dose delivered with $0 \mathrm{mg} / \mathrm{ml}$ of iodine and $20 \%$ of the maximum dose with $15 \mathrm{mg} / \mathrm{ml}$ of iodine contrast. It should be noted that in clinical practice only concentrations of up to $5 \mathrm{mg} / \mathrm{ml}$ are routinely achieved using standard intravenous injection techniques. Iodine concentrations above $15 \mathrm{mg} / \mathrm{ml}$ were found to result in less homogenous dose distributions within the tumor. The $10 \mathrm{MV}$ treatment was more uniform than the CTRx treatment and also had a smaller skull dose.

Rose et al. later published the results of a phase I clinical trial in which 8 patients with metastatic brain lesions smaller than $2.5 \mathrm{~cm}$ in diameter were treated with a modified CT scanner [26]. The CT scanner was set to $140 \mathrm{kVp}$ for treatment. The patients were injected with iodine contrast and received 3 to 5 weekly fractions of $5 \mathrm{~Gy}$. Each patient had at least one other metastatic brain lesion which did not receive CTRx and served as a control. The patients also received conventional whole brain radiotherapy either before, during or after their CTRx treatment. The authors reported that no patients demonstrated any side effects from the 

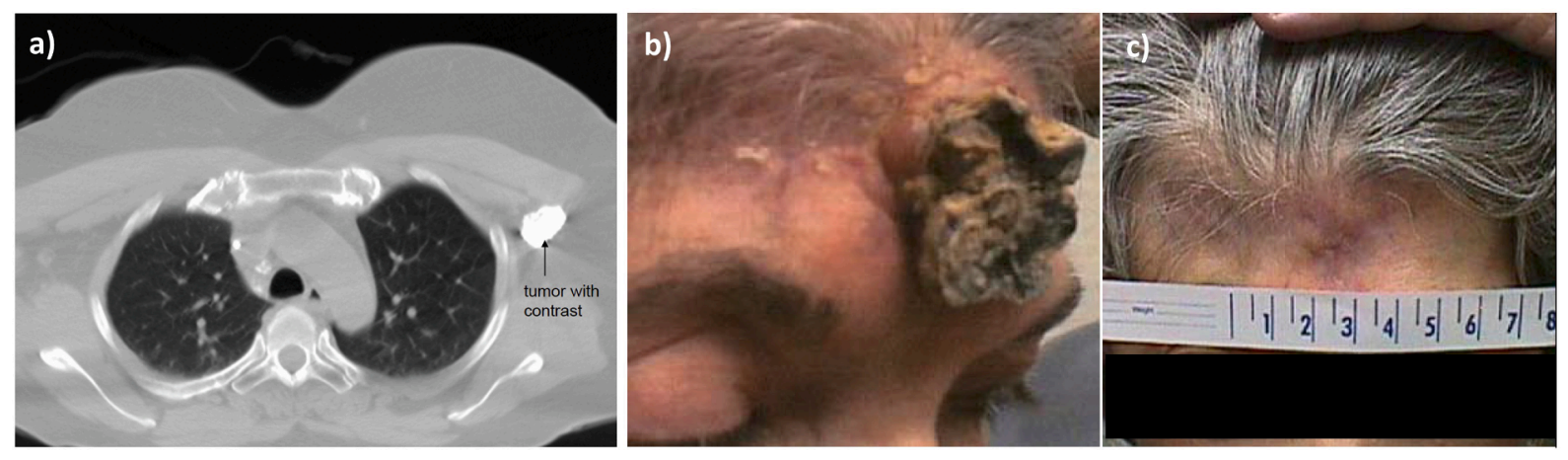

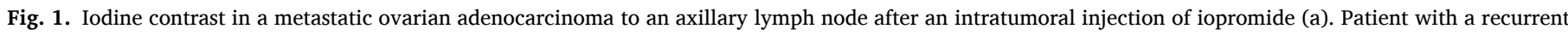

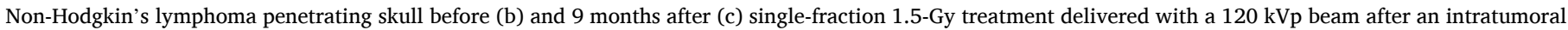
iopromide injection.

CTRx. Of the eight patients, the irradiated tumors shrank in six cases, remained constant in one case and grew in one case. The control tumors shrank in four cases, grew in two cases and remained constant in one case. The control tumor data for one patient was not available. The authors conclude that CTRx treatment is safe and that an advanced version of the CTRx system could provide diagnostic and therapeutic treatment for select patients.

Between 1997 and 1999, Weil et al. explored the safety of kV radiotherapy with dose enhancement using mostly directly injected iodine contrast for palliation of advanced cancers of different histologies in a Phase I/II human trial (unpublished data). The study was conducted in a university setting under IRB oversight. Eleven patients with recurrent disease in a variety of sites ranging from extremities to brain and liver were treated via CT-guided intralesional injection of $0.5-4.5 \mathrm{ml}$ of iopromide with $37 \% \mathrm{w} / \mathrm{v}$ iodine using a $120 \mathrm{kVp}$ beam of a radiotherapy simulator (Fig. 1a). The spatial distribution and concentration of iodine contrast in the tumors was derived from the Hounsfield numbers of the CT image in near real time. Thereby, the dose enhancement and dosimetry of the $\mathrm{kV}$ beam was optimized for each treatment. Several significant responses were noted with no skin reaction or sequelae attributable to RT. For example, a patient with multiply recurrent nonHodgkin's lymphoma on the forehead completely responded to a single 1.5-Gy treatment fraction delivered with contrast-enhanced RT (CERT) and underwent successful reconstructive surgery to cover a skull defect as the tumor had previously penetrated the bone (Fig. 1b-c).

\subsection{Veterinary applications}

Radiation therapy options for companion animals include the use of kV x-rays. In 1997, Norman et al. performed a study in which canines diagnosed with brain tumors were treated with the CTRx system mentioned above [27]. The study involved $47 \mathrm{dogs}$ from private households. The modified CT scanner was equipped with two separate collimators, the standard imaging collimator and a custom collimator for treatment. The dogs were treated with weekly fractions of $5.6 \mathrm{~Gy}$ using $140 \mathrm{kVp}$ x-rays on the CTRx after anesthetization and intravenous injection of iodinated contrast $(280 \mathrm{mg} / \mathrm{ml})$. The iodine-based contrast was used both for improved localization of the tumor and a dose enhancement effect. The tumor was located using the diagnostic imaging function of the CTRx after which the lesion was positioned at isocenter. The tumors were treated with the therapy collimator set to a rectangular aperture of $1 \mathrm{~cm}$ by $3 \mathrm{~cm}$. The scanner delivered the radiation using a scan speed of $4 \mathrm{~s}$ per rotation with a total of 60 rotations per fraction. The gantry was tilted at $-20,0$ and 20 degrees for 20 rotations each to deliver non-coplanar beams. The median survival for all treated canines was 133 days. However, the authors note that many owners decided to euthanize their animals early during treatment which decreased the median survival. The median survival of animals that completed treatment (defined as 6 or more fractions) was 231 days. Furthermore, the median survival of the canines who completed treatment was similar to previously published data of canines treated with cobalt therapy and orthovoltage therapy for brain tumors. In comparison, historical studies of the survival of canines with brain tumors suggest a median survival of $6-13$ days. Autopsies of canines who received CTRx treatment indicated no damage to healthy brain tissue, bone or skin. The authors concluded that CTRx treatment of brain tumors in canines was a safe and effective method.

Radiotherapy treatment options for companion animals are somewhat limited as linear accelerators are too costly for most veterinary hospitals to own. $\mathrm{kV}$ x-ray systems may be more suitable for companion animal radiation therapy due to their lower cost and, in addition, companion animals are smaller than humans and therefore involve much shallower treatment depths, which makes them ideal for lower energy $\mathrm{kV}$ x-ray treatment.

In 2018, Seo et al. published an article investigating the treatment of cancer in companion animals (canines) with 300 and $450 \mathrm{kV}$ x-rays [28]. The authors used numerical methods to calculate dose distributions using $300 \mathrm{kV}, 450 \mathrm{kV}$ and $6 \mathrm{MV}$ photons for brain, nasal cavity, forefoot and abdomen cancers in companion animals. Dose distributions were evaluated by means of DVH, homogeneity index and conformity index. DVH analysis indicated that all three x-ray beam energies yielded comparable dose distributions for brain and nasal tumors. The metrics of homogeneity and conformity index were optimal for the $6 \mathrm{MV} \mathrm{x}$-rays for the nasal, forefoot and abdominal tumors. The authors noted that in general dose to at-risk organs was less for the $6 \mathrm{MV}$ x-rays but was not significantly higher for the $\mathrm{kV}$ x-rays.

\subsection{Preclinical applications}

\subsubsection{Dose enhancement with gold nanoparticles}

Due to their biocompatibility, gold nanoparticles (AuNP) have been most commonly investigated for RT dose enhancement. Hainfeld et al. in 2004 irradiated tumors of mice with subcutaneous EMT-6 mammary carcinomas after an injection of AuNP with $250 \mathrm{kVp}$ x-rays [29]. Oneyear survival of $86 \%$ was significantly higher than the $20 \%$ survival after radiation alone and $0 \%$ with AuNP alone.

Many following computational, in vitro and in vivo studies demonstrated the NP radiosensitization effect with $\mathrm{kV}$ x-ray beams and an overview of the topic can be found in [30]. As expected, computational Monte Carlo dose calculation studies clearly show that NP dose enhancement in $\mathrm{kV}$ x-ray beams is in the order of $30-40 \%$ and it is negligible in the more penetrating clinically relevant MV photon beams. However, Jain et al. demonstrated a $41 \%$ and $29 \%$ dose enhancement in a $160 \mathrm{kVp}$ and $6 \mathrm{MV}$ x-ray beam for breast cancer MDA-MB-231 cells [31]. The same study presented no dose enhancement in normal L132, prostate cancer DU145 cells at $\mathrm{kV}$ or MV energies, suggesting that 
A Dose profile at entrance plane
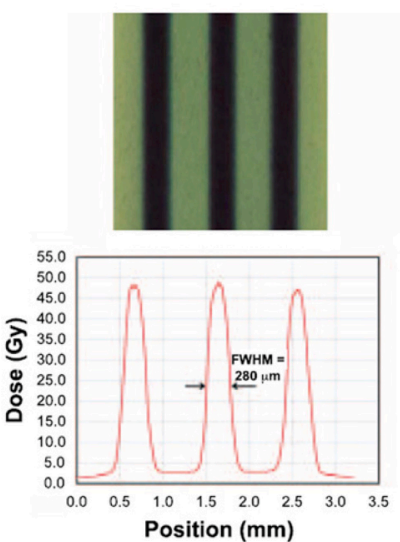

B
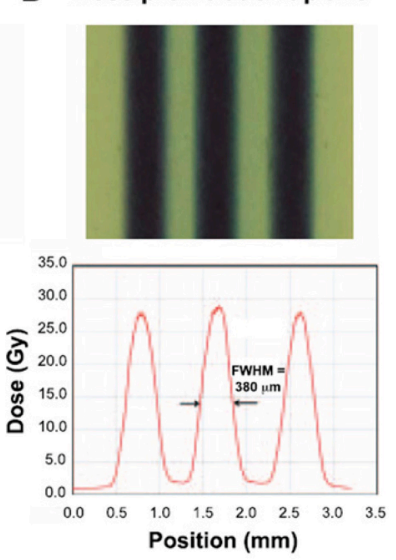

C
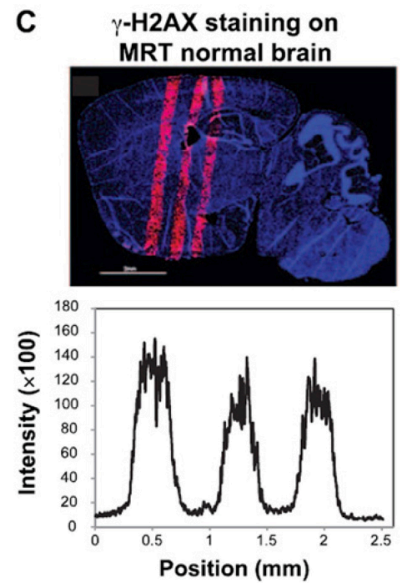

D
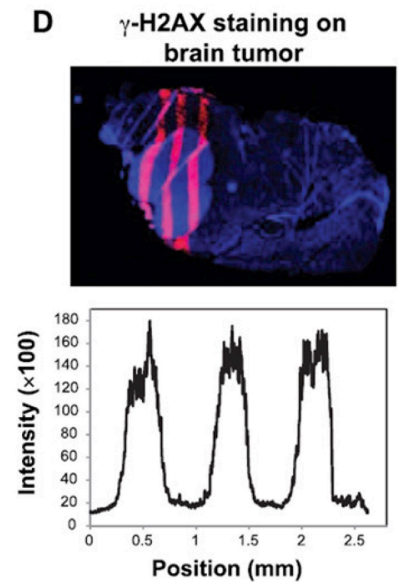

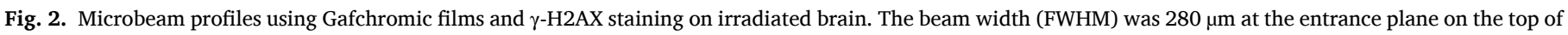

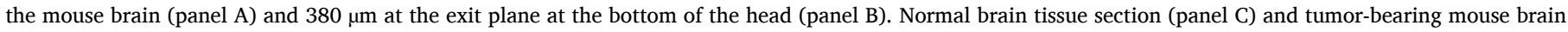

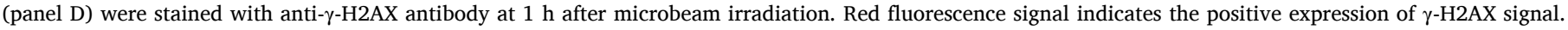

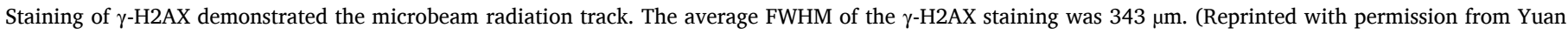

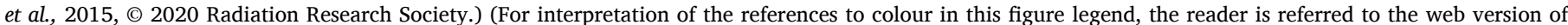
this article.)

radiosensitization even with $\mathrm{kV}$ x-ray beams is cell specific. Regardless, $\mathrm{kV}$ x-ray beams are most suitable for dose enhancement in combination with NP therapy. Thanks to their shallow tissue penetration, $\mathrm{kV}$ x-ray beams in the arrangement of rotational therapy described in section 3.4 might be best suited for optimal results of NP radiosensitization.

\subsubsection{Microbeam radiation therapy (MRT)}

In MRT, radiation is not delivered in the conventional broad-beam pattern, but it is delivered with an array of parallel 100-300 $\mu$ m wide beams separated by $100-300 \mu \mathrm{m}$. Compared to MV beams, $\mathrm{kV}$ x-ray beams are better suited for MRT delivery. Due to the short range of secondary electrons, the spatial fractionation of the beam can be preserved in tissue. MRT has been mostly delivered with high-brilliance synchrotron beams at dose rates of $>100 \mathrm{~Gy} / \mathrm{s}$ and has shown to improve normal tissue sparing while maintaining tumor control [32]. For example, Dilmanian et al. irradiated rat intracranial 9L gliosarcoma with various arrangements of microbeam size and spacing on the BNL synchrotron beamline with a mean x-ray beam energy of $70 \mathrm{keV}$. The median survival of a subset of rats was 170 days compared to the previously reported 34-day survival of similar models irradiated with a broad beam [33]. In 2003, subcutaneous mouse models of ENT-6 murine mammary carcinoma were irradiated with microbeams and a broad beam on the same beamline using x-ray beams with mean energy of 100 or $118 \mathrm{keV}$ [34]. Tumor ablation rates were higher and normal-tissue toxicity, acute (moist desquamation and epilation) and delayed (failure of hair regrowth), was lower for MRT compared to the broad beam irradiation.

Hadsell et al. investigated whether high dose-rate MRT can be delivered using a $50 \mathrm{kV}$ anode voltage and $0.5 \mathrm{~mA}$ beam current CNT xray source [35]. Based on their experimental pilot study they concluded that the required MRT pattern could be achieved with a CNT x-ray source, however, their setup only allowed for a dose rate of $1.54 \mathrm{mGy} / \mathrm{s}$. The authors predicted that a CNT x-ray source with a $160 \mathrm{kV}$ anode voltage and $1 \mathrm{~A}$ beam current would be required for a $100 \mathrm{~Gy} / \mathrm{s}$ dose rate delivery of MRT. In their follow-up work, the group at University of North Carolina has built a compact prototype MRT system with $160 \mathrm{kV}$ anode voltage and $30 \mathrm{~mA}$ beam current and delivered 2-3-beam MRT to mouse models of glioblastoma multiforme (GBM) with a skin dose rate of $1.2 \mathrm{~Gy} / \mathrm{min}$ [36]. The evidence of DNA double-strand breaks in the path of the microbeams was demonstrated via $\gamma$-H2AX staining. Yuan et al. irradiated mouse GBM models reaching 48 Gy and 72 Gy dose levels with MRT (Fig. 2) versus $10 \mathrm{~Gy}$ with broad beam and found similar survival when employing 72-Gy irradiation or $10 \mathrm{~Gy}$ broad beam irradiation [37]. A review of the group's MRT work with CNTs can be found in [38].

In 2011, Le Duc et al. presented a study combining the delivery of gadolinium-based nanoparticles (GBN) with MRT performed at the ID17 ESRF beamline for the treatment of a rats bearing intracerebral 9L gliosarcoma [39]. When MRT irradiation using cross-fired $25-\mu \mathrm{m}$ microbeams separated by $200 \mu \mathrm{m}$ gaps was delivered 20 min post GBN injection, median survival increased to 90 days compared to 19 days and 47 days for no treatment and MRT treatment without GBN, respectively. Interestingly, the median survival decreased to 34 days when MRT was delivered only $5 \mathrm{~min}$ after the injection of GBN. The authors concluded that the ratio of GBN concentration in the tumor to GBN concentration in normal tissue is a critical radiosensitization parameter rather than GBN concentration in the tumor itself.

\subsubsection{FLASH therapy}

Possibly the most recent application of kV x-rays in RT is the delivery of $>40 \mathrm{~Gy} / \mathrm{s}$ ultrahigh dose-rate (FLASH) RT. After initial studies in the late $1960 \mathrm{~s}$ [40,41], ultrahigh dose-rate RT was rediscovered in 2014 by Favaudon et al. [42]. In their study, the authors irradiated thoraxes of mice with a $4.5 \mathrm{MeV}$ electron beam with a dose rate of $40 \mathrm{~Gy} / \mathrm{s}$ and reported a significant decrease in radiation-induced lung fibrosis when compared to conventional irradiations at a dose rate of $0.03 \mathrm{~Gy} / \mathrm{s}$ performed with a ${ }^{137} \mathrm{Cs}$ gamma ray source. Most clinical RT is performed with $\mathrm{x}$-ray beams and there was interest to investigate whether the FLASH effect can be also triggered with an x-ray beam. Due to engineering challenges of accelerator-based megavoltage $\mathrm{x}$-ray beam generation at high dose rates, a synchrotron source was chosen for this purpose.

In 2018, mouse whole brain irradiations (WBI) were performed with the ID17 ESRF beamline using a thin $50-\mu \mathrm{m}$ wide synchrotron $\mathrm{x}$-ray beam scanned across the mouse brain at an in-slice dose rate of 12,000 $\mathrm{Gy} / \mathrm{s}$ and a mean brain dose rate of $37 \mathrm{~Gy} / \mathrm{s}$ [43]. The conventional lowdose rate WBI was delivered with the $225 \mathrm{kVp}$ beam on the imageguided small animal radiation research platform (SARRP). After a 10Gy brain dose, unlike after the conventional SARRP irradiation, no induction in memory deficit was observed after FLASH irradiation and the case for normal tissue sparing of $\mathrm{x}$-ray FLASH was therefore strengthened.

More recently, Bazalova-Carter and Esplen have proposed that it might be possible to use conventional x-ray tubes to deliver ultrahigh 


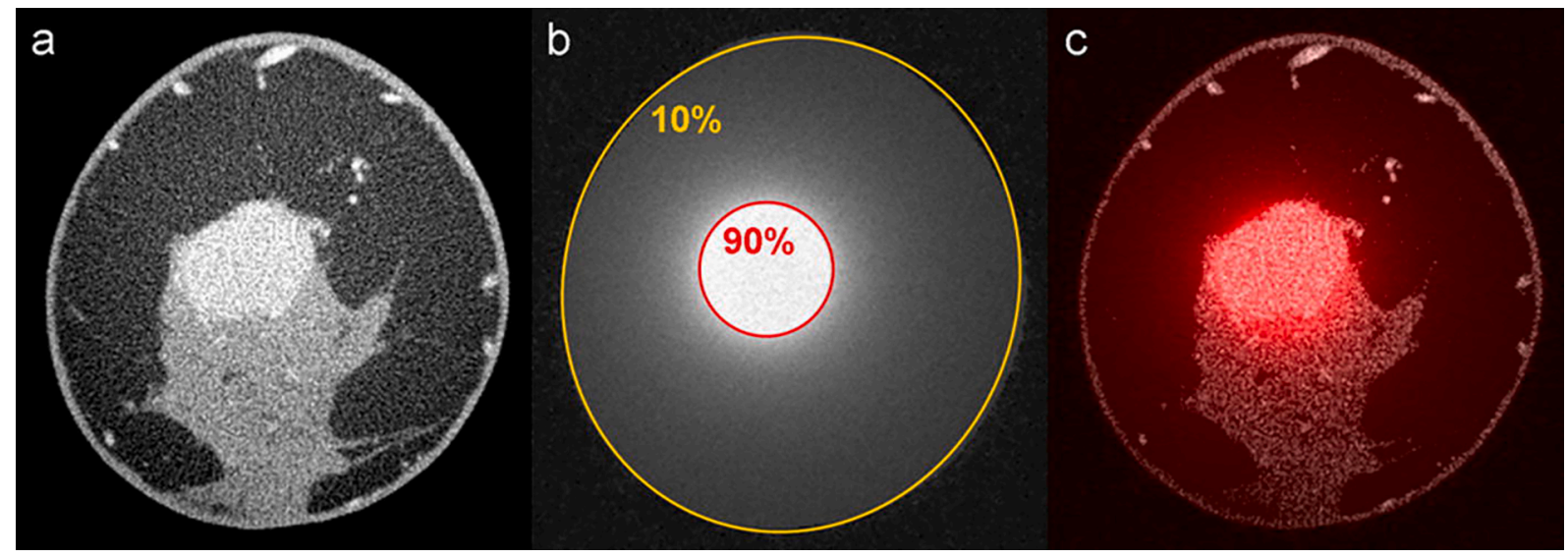

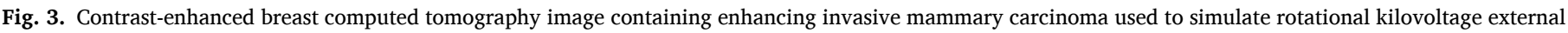

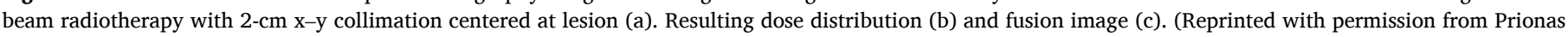
et al., 2012.)

dose-rate RT [44]. Dose rates of $>40 \mathrm{~Gy} / \mathrm{s}$ can be achieved for an unfiltered $\mathrm{x}$-ray beam at shallow $<1 \mathrm{~mm}$ depth in a sample placed at the x-ray tube surface. The FLASH effect, however, has not yet been investigated with this continuous $\mathrm{x}$-ray source. A comprehensive review of FLASH therapy can be found in [63].

\subsection{Proof-of-principle and computational models}

\subsubsection{Kilovoltage external beam radiotherapy $(k V-E B R T)$}

Dedicated breast CT (bCT) platforms were first developed in 2008 in order to improve the diagnosis of breast cancer [45]. In 2012, Prionas et al. published work investigating rotational kilovoltage external beam radiation therapy (kV-EBRT) of breast cancer with $320 \mathrm{kVp}$ x-rays using a bCT system [46]. kV-EBRT was simulated using Monte Carlo methods for both cylindrical phantoms and breast CT data. The beam was simulated and $2 \mathrm{D}$ and $3 \mathrm{D}$ dose distributions were generated with a range of collimation settings. The smallest diameter was $1 \mathrm{~cm}$ and the largest was $14 \mathrm{~cm}$ in the XY plane. Z collimation was $0.1 \mathrm{~cm}$ for 2D profiles and $2 \mathrm{~cm}$ for 3D dose distribution. Smaller XY collimation settings demonstrated centrally peaked dose deposition with the $1 \mathrm{~cm}$ setting depositing as little as $7 \%$ dose at the periphery of the cylindrical phantom. The $14 \mathrm{~cm}$ collimation setting resulting in a centrally cupped dose distribution.

Experimental validation was performed using a CT scanner operating at a tube voltage of $120 \mathrm{kV}$. Dose measurements of the radial dose distributions in a 14-cm diameter polyethylene cylinder were made using an ionization chamber. These measurements were compared to Monte Carlo simulated radial dose distributions with a matched energy spectrum. The mean percentage of difference between the simulated and measured dose distributions was $10.5 \%+-7.7 \%$ for the $1-\mathrm{cm}$ collimated beam and $2.8 \%+-2.3 \%$ for the $14-\mathrm{cm}$ collimated beam.

The authors also investigated whole breast irradiation using phantoms, dose "painting" and the treatment of patients with Monte Carlo simulations. Of particular note are the simulations of a breast cancer patient imaged with iodine contrast (Fig. 3). Using a $2 \mathrm{~cm}$ collimated beam, the calculated dose distribution shows that the lesion was contained within the $90 \%$ isodose line and that the skin received $10 \%$ of the maximum dose.

A number of follow-up studies on breast kV-EBRT were published by a group at the University of Naples. In 2019, Buonano et al. published a similar study to the one by Prionas et al., in which they investigated breast phantom dose distributions achieved by 150,300 , and $320 \mathrm{kVp} \mathrm{x}$ ray beams generated by an $\mathrm{x}$-ray tube by means of MC simulations and experiments [47]. Rotational kV-EBRT permitted a periphery-to-center dose ratio from $13 \%$ to $9 \%$ in homogeneous breast phantoms of $14-\mathrm{cm}$ in diameter for beams of $\sim 1 \mathrm{~cm}$ in size. Earlier the group investigated breast EBRT with a synchrotron beam termed synchrotron radiation rotational radiotherapy $\left(\mathrm{SR}^{3} \mathrm{~T}\right)$ by means of $\mathrm{MC}$ simulations and experiments with the same 14-cm diameter phantom $[48,49]$. They performed Geant4 simulations and measurements with Gafchromic films, ionization chambers and TLD of phantom dose delivered with monoenergetic 60-175 keV synchrotron x-ray beams at the Australian Synchrotron
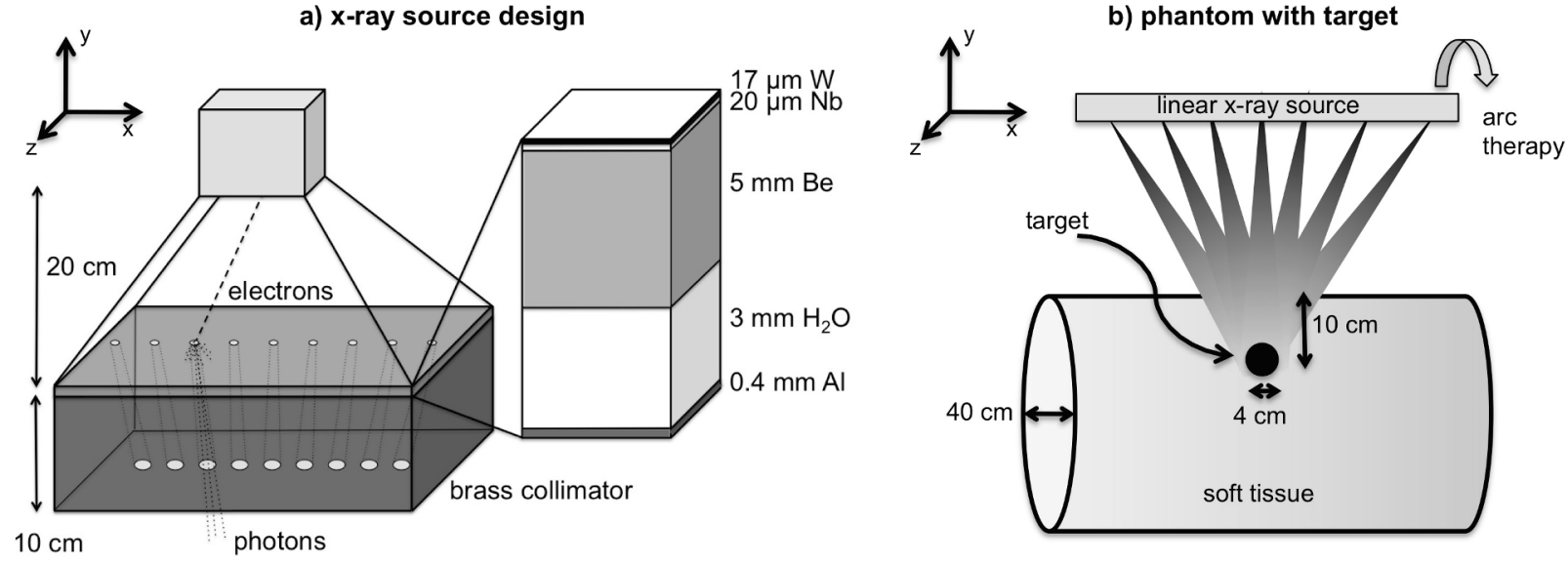

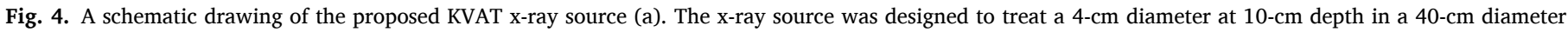
cylinder using arc therapy (b). (Reprinted with permission from Bazalova-Carter et al., 2017.) 
IMBL. They calculated and measured a tumor-to-skin absorbed dose ratio ranging from about 7:1 (at $60 \mathrm{keV}$ photon energy) to about 10:1 (at $175 \mathrm{keV}$ ) for a $1.5-\mathrm{cm}$ wide beam, which was deemed sufficient for skin sparing during radiotherapy.

\subsubsection{Kilovoltage $x$-ray beam arc therapy}

In the EBCT and SBDX x-ray sources electron beam energies of 80-140 keV are used, resulting in an x-ray beam with shallow dose deposition and not suitable for radiotherapy. To overcome this shortcoming, a design of a stationary-anode source was modeled for the delivery of kilovoltage arc therapy (KVAT) to deep-seated tumors employing non-coplanar kV beams (Fig. 4). First, a source design study was performed to optimize the delivery of conformal radiation to a 4-cm diameter, $10-\mathrm{cm}$ deep lesion by varying beam energy, $\mathrm{x}$-ray beam filtration, target thickness and collimator design [50]. Several follow-up studies published by Breitkreutz et al. are described briefly below.

The first publication by Breitkreutz et al. involved Monte Carlo simulations of a novel geometry, scanning electron-beam x-ray tube design which produces a non-coplanar linear array of x-ray beamlets with an energy of $200 \mathrm{kV}$. The system was designed with a gantry to allow $360^{\circ}$ rotation around the patient. The scanning nature of the x-ray tube allows for adjustment of beamlet dwell times to produce true intensity modulated therapy. Proof-of-principle simulations were first used with a transmission anode design. These simulations for cylindrical water phantoms indicated that a skin sparing effect could be produced while delivering a dose rate up to $345 \mathrm{cGy} / \mathrm{min}$ for a $1-\mathrm{cm}$ diameter spherical target, with dose rates decreasing at greater target size and depth [51].

Further work employed Monte Carlo simulations to investigate the treatment of lung, breast and prostate cancer using inversely optimized treatment planning [52]. These simulated $\mathrm{kV}$ treatments were compared to MV photon treatments for reference. Dose constraints taken from RTOG reports were used to evaluate the breast, lung and prostate KVAT plans and were met in all cases. However, the KVAT prostate plan likely was untreatable due to lengthy delivery times and suboptimal dosimetry for healthy tissues. This was due primarily to the size of the patient, the less penetrating radiation and avoidance of bony anatomy. One limitation of this study was the use of idealized, spherical lesions as tumor targets.

Lastly, Breitkreutz et al. simulated KVAT of lung tumors with realistic lung lesions based on CT scan data from three lung cancer patients [53]. In this study, the KVAT model was modified to a reflection anode. The location of the lung tumors varied in each patient. It was found that for a patient with a tumor directly next to the chest wall that the rib dose may exceed dose constraints. All other dose constraints were met for each patient.

In summary, the KVAT $\mathrm{x}$-ray source has been developed to address $\mathrm{kV}$ shortcomings by rapidly distributing multiple $\mathrm{kV}$ beams via electronic manipulation rather than with conventional mechanical control. It focuses dose deposition while dispersing entrance dose and overrides attenuation constraints of lower energy $\mathrm{x}$-rays and thereby enables less expensive $\mathrm{kV}$ x-ray technology for radiotherapy treatment.

The KVAT system is the main component of the linear converging radiotherapy system (LCRS) under development by PrecisionRT (Las Vegas, NV, USA). The LCRS will be capable of simultaneous tomosynthesis imaging of real-time tumor motion and radiation therapy delivery [54]. Thanks to the addition of a detector, the source can create CT scans and image in real-time during therapy without a separate CT unit. Simulations have demonstrated the design can plan and complete effective therapy within one hour. Most of these models demonstrated equivalent performance to MV volumetric modulated arc therapy (VMAT) at $10 \%$ of the cost per system and likely reducing cost per patient to US $\$ 100$ or less.

It will be possible to house the LCRS in a conventional 3.2-mm thick, lead-lined room found in most clinics or in a mobile trailer. The treatment planning software currently under development will be capable of
Table 1

Summary of benefits and drawbacks of kV RT compared to MV RT.

\begin{tabular}{|c|c|c|c|c|}
\hline \multirow{3}{*}{$\begin{array}{l}\text { Skin dose } \\
\text { Dose fall off }\end{array}$} & \multicolumn{2}{|c|}{ kV RT (200 kV) } & \multicolumn{2}{|c|}{ MV RT (6 MV) } \\
\hline & high & $\left(\sim 100 \%\right.$ of $\left.D_{\max }\right)$ & low & $\left(40 \%\right.$ of $\left.D_{\max }\right)$ \\
\hline & fast & $\begin{array}{l}\left(20 \% \text { of } D_{\max } \text { at } 10\right. \\
\text { cm depth) }\end{array}$ & slow & $\begin{array}{l}\text { (70\% of } D_{\max } \text { at } 10 \\
\text { cm depth) }\end{array}$ \\
\hline $\begin{array}{l}\text { Range of } \\
\text { secondary } \mathrm{e}^{-}\end{array}$ & short & $(1-2 \mathrm{~mm})$ & long & $(\sim 1-2 \mathrm{~cm})$ \\
\hline Treatment time & long & $(\sim 20 \mathrm{~min})$ & short & $(\sim 2 \mathrm{~min})$ \\
\hline Shielding & thin & $(\sim 2 \mathrm{~mm}$ lead $)$ & thick & $(\sim 2$ m concrete $)$ \\
\hline Machine cost & low & (US\$200,000) & high & (US\$3,000,000) \\
\hline
\end{tabular}

optimizing a radiosurgical treatment prescription. The patient will be immobilized and aligned per conventional techniques. Thanks to machine learning (ML), treatment planning and delivery will be performed in a matter of minutes, slightly more time than it takes to do a diagnostic scan [55].

\subsubsection{BriXS source for rotational breast radiotherapy}

In 2019, Sarno et al. published work investigating the use of a BriXS twin Compton pulsed x-ray source as an alternative source for the treatment of breast cancer [56]. The BriXS source has a physical footprint of $40 \mathrm{~m}$ by $20 \mathrm{~m}$ and produces an x-ray spectrum with a mean energy of $88 \mathrm{keV}$ with a high photon flux suitable for radiation therapy. The Geant4 Monte Carlo software was used to simulate rotational radiotherapy of breast cancer using the BriXs source. The breast was modelled as a $14 \mathrm{~cm}$ diameter cylinder with a $1 \mathrm{~cm}$ circular lesion at the center and off-axis. The modeled beam was rotated $360^{\circ}$ around the cylinder to simulate a prone breast geometry. The main metric used to evaluate the simulated dose distributions was skin-to-tumor dose ratio. The skin-to-tumor dose ratio was $7 \%$ for the central lesion and $36 \%$ for the off-axis lesion.

\subsubsection{Kilovoltage intensity modulated radiotherapy}

In 2019, a group at Wayne State University presented a MC computer model and a proof-of-principle experiment for a kilovoltage intensity modulated radiotherapy (IMRT) for the treatment of GBM by means of CERT with iodine [57]. They used Geant4 to simulate dose deposition in a 15-cm diameter spherical water phantom with a 1.4-cm thick spherical shell mimicking the skull and a target of $1.8-\mathrm{cm}$ in diameter filled with $10 \mathrm{mg} / \mathrm{mL}$ of iodine. A CERT IMRT treatment with 17 heavily tungstenfiltered $120 \mathrm{kVp}$ coplanar beams, the dose to the target was by a factor of 3-4 higher than dose to the skull. The proof-of-principle experiment was performed with an in-house multi-rod collimator using a set of deliveries and phantoms with radiochromic films. A good agreement between a 3D conformal radiotherapy plan delivery and its MC dose calculation was found. The main limitation of the proof-of-principle system was found in the delivery time, that was from 3 to $20 \mathrm{~h}$ long for the IMRT plans.

\section{Benefits and drawbacks of $\mathrm{kV}$ radiotherapy}

While there are benefits of $\mathrm{kV}$ radiotherapy listed in section 1.2 , there are also practical drawbacks to the use of $\mathrm{kV} \mathrm{x}$-rays for the treatment of deep-seated tumors. The benefits and drawbacks are briefly summarized in qualitative and quantitative terms in Table 1.

The first consideration is the limitation of $\mathrm{kV} x$-ray beam penetration. Kilovoltage x-ray beams are characterized by no build-up and therefore maximum dose deposition $D_{\max }$ occurs in a patient's skin. This is problematic as any dose delivered to a target below the surface will necessitate a larger dose to the tissue above it, which can be problematic unless beams from multiple directions intersecting at the target are used. Secondary electrons produced by $\mathrm{kV}$ x-rays have less energy and a shorter range than those created by MV x-rays resulting in a smaller percentage of the maximum dose being delivered at larger depths. This fact compounds the problem of delivering dose to a lesion below the surface. On the other hand, the shorter range of secondary electrons is 
responsible for the sharper beam penumbra in $\mathrm{kV}$-ray beams compared to MV x-rays. When compared to MV x-rays the faster fall-off of $\mathrm{kV} \mathrm{x}$-ray beam dose results in lower exit dose. The lack of penetration of $\mathrm{kV} x$-rays is the primary reason why novel $\mathrm{kV}$-based technologies use more complex source geometry and delivery techniques to reduce surface dose.

Treatment times of $\mathrm{kV}$ x-ray sources for deep-seated lesions can also be problematic. Due to the physics of the bremsstrahlung process, a lower percentage of the $\mathrm{kV}$ electrons incident on the bremsstrahlung target is converted into photons compared to MV electrons resulting in the generation of a large amount of heat. Ultimately, there is a practical limit to the electron current at which an x-ray tube may be safely operated, which limits its achievable dose rate. This causes problems for patient treatment as delivery times will be longer than systems using MV $\mathrm{x}$-rays. Longer treatment times will result in less patient comfort and problems associated with patient motion during treatment, if not addressed by real-time imaging.

\section{Other considerations}

Kilovoltage x-rays have been used for the treatment of cancer alongside MV x-rays for decades. For treatments of deep-seated tumors, a number of challenges for $\mathrm{kV}$ therapy compared to MV therapy exist, such as the increased treatment time, dose calculation complexity, potential differences in radiobiology between $\mathrm{kV}$ and MV beams. Some of these topics for external beam kV RT are discussed here.

\subsection{Clinical consideration}

Consideration of normal tissue and tumor control probability can be derived from the hypo-fractionated protocols conventionally employed in the clinic [58]. For example, the presence of a higher cross-section of cortical bone to $\mathrm{kV}$ x-rays might limit use of certain beam angles when planned per accepted tolerances. Even though it is mostly accepted that cell killing potential for $\mathrm{kV}$ and MV x-rays is similar [59], some literature suggests differences in the radiobiology of $\mathrm{kV}$ and MV beams exist [60]. There is no compelling support in the literature for significant differences in the radiobiology of the respective beam energies. Therefore, the dose effects are considered similar, except for the significant enhancement possible in the presence of high- $Z$ contrast agents described in sections 3.1.3 and 3.3.1.

\subsection{Economic considerations}

There are three macro trends in healthcare that could affect use of a $\mathrm{kV}$ treatment system. First, cancer therapy is a growing concern as the populations in developing countries age. Longer life spans and changes with economic advances are associated with increased incidence of cancer, e.g., lung cancer is rising dramatically in Asia due to high tobacco consumption. At the same time, since standard treatment is costly and complex, the additional population burdens on advanced care could make it more inaccessible in the majority of developing economies where finances and infrastructure are limited. Second, the consolidation and squeezing of hospitals and third-party payers (insurers, businesses and government) caused by the 2020 pandemic has decreased cases and income for technical and professional oncology billing. If this trend continues, it will put pressure on a portion of the market and some facilities may have to forgo high-end construction and equipment. Finally, the successful introduction of immuno-oncologic and targeted drug therapies is making significant inroads in cancer care, and is also of import in delivering palliative care. Given their improved prospects to slow a tumor's growth, a patient might live with a protracted malignancy, which requires additional loco-regional control. Thus, if a new cancer therapy induces chronic or stable disease, such disease status can potentially lead to more treatments with $\mathrm{kV}$ radiotherapy for adjuvant or palliative care.

Of note, some predictions can be made in terms of the number of
Table 2

Projections on annual $\mathrm{kV}$ teletherapy cases for the USA.

\begin{tabular}{llll}
\hline Site & Total Cases $^{1}$ & Treatable fraction $^{2}$ & Projected \# patients \\
\hline Bone, secondary & 208,000 & 0.90 & 187,000 \\
Breast & 266,000 & 0.50 & 133,000 \\
Lung, primary & 234,000 & 0.60 & 140,000 \\
Total & 708,000 & & 460,000 \\
\hline
\end{tabular}

1 National Cancer Institute, SEER Cancer Statistics Review [61].

2 Treatable fraction based on advanced stage, technical feasibility and referral patterns.

patients treated by converging $\mathrm{kV}$ teletherapy, e.g. the LCRS source, in the USA thanks to data collected by the National Cancer Institute (NCI) [61]. Previous in silico studies have demonstrated that lung and breast are suitable sites for the effective application of converging $\mathrm{kV}$ teletherapy due to their reduced attenuation of the beams [52]. In addition, though the increased dose to bone might limit dose escalation for most treatment sites, it can be exploited for the focused $\mathrm{kV}$ treatments of bone metastases. Under the assumption that approximately $50 \%$ of cancer patients receive conventional radiotherapy for local control, and an estimated $50-90 \%$ likelihood of referrals, it can be predicted that in the USA alone, about 460,000 patients with bone, breast and lung cancer might be treated annually (Table 2).

\section{Conclusions}

In this review article, we have provided a brief overview of a number of radiotherapy techniques employing kilovoltage $\mathrm{x}$-rays for treatments of cancer. We summarized the potential benefits and drawbacks of the currently investigated treatment modalities and discussed the importance of developing low-cost radiotherapy.

\section{Acknowledgements}

The authors would like to acknowledge the support of the Canada Research Chairs program and the Natural Sciences and Engineering Research Council (NSERC).

\section{References}

[1] Laissue JA, Blattmann H, Slatkin DN. Alban Köhler (1874-1947): Erfinder der Gittertherapie. Zeitschrift für Medizinische Physik 2012;22(2):90-9. https://doi. org/10.1016/j.zemedi.2011.07.002.

[2] Kerr DJ, Midgley R. Can We Treat Cancer for a Dollar a Day? Guidelines for LowIncome Countries. N Engl J Med 2010;363(9):801-3. https://doi.org/10.1056/ NEJMp1002812.

[3] Stathakis S. The Physics of Radiation Therapy. Med. Phys. 2010;37(3):1374-5. https://doi.org/10.1118/1.3319185.

[4] Rand RE. Scanning electron beam computed tomography scanner with ion aided focusing. Google Patents 1985.

[5] Van Lysel MS, Solomon EG, Wilfley BP, Dutta A, Speidel MA. Performance assessment of the scanning beam digital X-ray (SBDX) system. Proceedings of the SPIE - The International Society for Optical Engineering. 1997;3032:161-70.

[6] Speidel MA, Wilfley BP, Star-Lack JM, Heanue JA, Van Lysel MS. Scanning-beam digital x-ray (SBDX) technology for interventional and diagnostic cardiac angiography: SBDX technology for interventional cardiac angiography. Med. Phys. 2006;33(8):2714-27. https://doi.org/10.1118/1.2208736.

[7] Dinsmore M, Harte KJ, Sliski AP, Smith DO, Nomikos PM, Dalterio MJ, Boom AJ, Leonard WF, Oettinger PE, Yanch JC. A new miniature x-ray source for interstitial radiosurgery: Device description. Med. Phys. 1996;23(1):45-52. https://doi.org/ 10.1118/1.597790.

[8] Rivard MJ, Davis SD, DeWerd LA, Rusch TW, Axelrod S. Calculated and measured brachytherapy dosimetry parameters in water for the Xoft Axxent X-Ray Source: An electronic brachytherapy sourcea): Dosimetry parameters for the Xoft Axxent XRay Source. Med. Phys. 2006;33(11):4020-32. https://doi.org/10.1118/ 1.2357021.

[9] Lei W, Li C, Cole MT, Qu Ke, Ding S, Zhang Y, Warner JH, Zhang X, Wang B, Milne WI. A graphene-based large area surface-conduction electron emission display. Carbon 2013;56:255-63. https://doi.org/10.1016/j.carbon.2013.01.004.

[10] Heo SH, Ihsan A, Cho SO. Transmission-type microfocus x-ray tube using carbon nanotube field emitters. Appl. Phys. Lett. 2007;90(18):183109. https://doi.org/ $10.1063 / 1.2735549$. 
[11] Parmee RJ, Collins CM, Milne WI, Cole MT. X-ray generation using carbon nanotubes. Nano Convergence 2015;2(1). https://doi.org/10.1186/s40580-0140034-2.

[12] Kim HJ, Ha JM, Heo SH, Cho SO. Small-Sized Flat-Tip CNT Emitters for Miniaturized X-Ray Tubes. J Nanomater 2012;2012:1-6. https://doi.org/10.1155/ 2012/854602.

[13] Serduc R, Bräuer-Krisch E, Siegbahn EA, Bouchet A, Pouyatos B, Carron R, et al. High-precision radiosurgical dose delivery by interlaced microbeam arrays of highflux low-energy synchrotron x-rays. PLoS ONE. 2010;5:1-12.

[14] Bräuer-Krisch E, Adam J-F, Alagoz E, Bartzsch S, Crosbie J, DeWagter C, Dipuglia A, Donzelli M, Doran S, Fournier P, Kalef-Ezra J, Kock A, Lerch M, McErlean C, Oelfke U, Olko P, Petasecca M, Povoli M, Rosenfeld A, Siegbahn EA, Sporea D, Stugu B. Medical physics aspects of the synchrotron radiation therapies: Microbeam radiation therapy (MRT) and synchrotron stereotactic radiotherapy (SSRT). Physica Med 2015;31(6):568-83. https://doi.org/10.1016/j. ejmp.2015.04.016.

[15] Laissue JA, Bartzsch S, Blattmann H, Bräuer-Krisch E, Bravin A, Dalléry D, Djonov V, Hanson AL, Hopewell JW, Kaser-Hotz B, Keyriläinen J, Laissue PP, Miura M, Serduc R, Siegbahn AE, Slatkin DN. Response of the rat spinal cord to Xray microbeams. Radiother Oncol 2013;106(1):106-11. https://doi.org/10.1016/j. radonc.2012.12.007.

[16] Huang Z, Ruth RD. Laser-Electron Storage Ring. Phys Rev Lett 1998;80(5):976-9. https://doi.org/10.1103/PhysRevLett.80.976.

[17] Bech M, Bunk O, David C, Ruth R, Rifkin J, Loewen R, Feidenhans'l R, Pfeiffer F. Hard X-ray phase-contrast imaging with the Compact Light Source based on inverse Compton X-rays. J Synchrotron Rad 2009;16(1):43-7. https://doi.org/ 10.1107/S090904950803464X.

[18] Drebot I, Bacci A, Bosotti A, Broggi F, Canella F, Cardarelli P, et al. BriXs ultra high flux inverse compton source based on modified push-pull energy recovery linacs. Instruments. 2019;3:49.

[19] Pilar A, Gupta M, Laskar SG, Laskar S. Intraoperative radiotherapy: review of techniques and results. Ecancermedicalscience. 2017;11.

[20] Dickler A, Ivanov O, Francescatti D. Intraoperative radiation therapy in the treatment of early-stage breast cancer utilizing xoft axxent electronic brachytherapy. World J Surg Onc 2009;7(1). https://doi.org/10.1186/1477-7819 7-24.

[21] Boese A, Johnson F, Ebert T, Mahmoud-Pashazadeh A, Arens C, Friebe M. Transoral miniature X-ray radiation delivery system with endoscopic optical feedback. Int J CARS 2017;12(11):1995-2002. https://doi.org/10.1007/s11548-017-1601-X.

[22] Mahmoud-Pashazadeh A, Illanes A, Joseph FJ, van Oepen A, Boese A, Friebe M. Miniature CNT-based X-ray tube: assessment for use in intraoperative radiation therapy: Miniature CNT-based X-ray tube. Current Directions in Biomedical Engineering. 2017;3:643-6.

[23] McGregor S, Minni J, Herold D. Superficial radiation therapy for the treatment of nonmelanoma skin cancers. J Clinic Aesth Dermatol 2015;8:12.

[24] Meitner L. Über die entstehung der $\beta$-strahl-spektren radioaktiver substanzen. Zeitschrift für Physik. 1922;9:131-44.

[25] Mesa AV, Norman A, Solberg TD, Demarco JJ, Smathers JB. Dose distributions using kilovoltage x-rays and dose enhancement from iodine contrast agents. Phys Med Biol 1999;44(8):1955-68. https://doi.org/10.1088/0031-9155/44/8/308.

[26] Rose JH, Norman A, Ingram M, Aoki C, Solberg T, Mesa A. First radiotherapy of human metastatic brain tumors delivered by a computerized tomography scanner (CTRx). Int J Rad Oncol Biol Phys 1999;45(5):1127-32. https://doi.org/10.1016/ S0360-3016(99)00347-8.

[27] Norman A, Ingram M, Skillen RG, Freshwater DB, Iwamoto KS, Solberg T. X-ray phototherapy for canine brain masses. Radiat. Oncol. Investig. 1997;5(1):8-14. https://doi.org/10.1002/(SICI)1520-6823(1997)5:1<8::AID-ROI2>3.0.CO;2-1.

[28] Seo J, Son J, Cho Y, Park N, Kim DW, Kim J, Yoon M. Kilovoltage radiotherapy for companion animals: dosimetric comparison of $300 \mathrm{kV}, 450 \mathrm{kV}$, and $6 \mathrm{MV}$ X-ray beams. J Vet Sci 2018;19(4):550. https://doi.org/10.4142/jvs.2018.19.4.550.

[29] Hainfeld JF, Slatkin DN, Smilowitz HM. The use of gold nanoparticles to enhance radiotherapy in mice. Phys Med Biol 2004;49(18):N309-15. https://doi.org/ 10.1088/0031-9155/49/18/N03.

[30] Haume K, Rosa S, Grellet S, Śmiałek MA, Butterworth KT, Solov'yov AV, Prise KM, Golding J, Mason NJ. Gold nanoparticles for cancer radiotherapy: a review. Cancer Nano 2016;7(1). https://doi.org/10.1186/s12645-016-0021-x.

[31] Jain S, Coulter JA, Hounsell AR, Butterworth KT, McMahon SJ, Hyland WB, Muir MF, Dickson GR, Prise KM, Currell FJ, O'Sullivan JM, Hirst DG. Cell-Specific Radiosensitization by Gold Nanoparticles at Megavoltage Radiation Energies. Int J Rad Oncol Biol Phys 2011;79(2):531-9. https://doi.org/10.1016/j. ijrobp.2010.08.044.

[32] Laissue JA, Geiser G, Spanne PO, Dilmanian FA, Gebbers J-O, Geiser M, Wu X-Y, Makar MS, Micca PL, Nawrocky MM, Joel DD, Slatkin DN. Neuropathology of ablation of rat gliosarcomas and contiguous brain tissues using a microplanar beam of synchrotron-wiggler-generated X rays. Int. J. Cancer 1998;78(5):654-60. https://doi.org/10.1002/(SICI)1097-0215(19981123)78:5<654::AID-IJC21>3.0. CO;2-L.

[33] Dilmanian FA, Button TM, Duc GL, Zhong N, Peña LA, Smith JAL, et al. Response of rat intracranial 9L gliosarcoma to microbeam radiation therapy. Neuro Oncol 2002;4:26-38

[34] Dilmanian FA, Morris GM, Zhong N, Bacarian T, Hainfeld JF, Kalef-Ezra J, Brewington LJ, Tammam J, Rosen EM. Murine EMT-6 Carcinoma: High Therapeutic Efficacy of Microbeam Radiation Therapy. Radiat Res 2003;159(5): 632-41. https://doi.org/10.1667/0033-7587(2003)159[0632:MECHTE]2.0.CO;2.

[35] Hadsell M, Cao G, Zhang J, Burk L, Schreiber T, Schreiber E, Chang S, Lu J, Zhou O. Pilot study for compact microbeam radiation therapy using a carbon nanotube field emission micro-CT scanner: Pilot study for MRT using CNT micro-CT scanner. Med Phys 2014;41(6Part1):061710. https://doi.org/10.1118/1.4873683.

[36] Zhang L, Yuan H, Burk LM, Inscoe CR, Hadsell MJ, Chtcheprov P, Lee YZ, Lu J, Chang S, Zhou O. Image-guided microbeam irradiation to brain tumour bearing mice using a carbon nanotube x-ray source array. Phys Med Biol 2014;59(5): 1283-303. https://doi.org/10.1088/0031-9155/59/5/1283.

[37] Yuan H, Zhang L, Frank JE, Inscoe CR, Burk LM, Hadsell M, et al. Treating brain tumor with microbeam radiation generated by a compact carbon-nanotube-based irradiator: initial radiation efficacy study. Radiation research. 2015;184:322-33.

[38] Zhang L, Yuan H, Inscoe C, Chtcheprov P, Hadsell M, Lee Y, Lu J, Chang S, Zhou O. Nanotube $\mathrm{x}$-ray for cancer therapy: a compact microbeam radiation therapy system for brain tumor treatment. Expert Rev Anticancer Ther 2014;14(12):1411-8. https://doi.org/10.1586/14737140.2014.978293.

[39] Le Duc G, Miladi I, Alric C, Mowat P, Bräuer-Krisch E, Bouchet A, Khalil E, Billotey C, Janier M, Lux F, Epicier T, Perriat P, Roux S, Tillement O. Toward an Image-Guided Microbeam Radiation Therapy Using Gadolinium-Based Nanoparticles. ACS Nano 2011;5(12):9566-74. https://doi.org/10.1021/ nn202797h.

[40] Todd P, Winchell H, Feola J, Jones G. Inactivation by pulsed high-intensity x-rays of human cells cultured in vitro. RADIATION RESEARCH: RADIATION RESEARCH SOC 2021 SPRING RD, STE 600, OAK BROOK, IL 60521; 1967. p. 644-\&.

[41] TOWN CD. Effect of High Dose Rates on Survival of Mammalian Cells. Nature 1967;215(5103):847-8. https://doi.org/10.1038/215847a0.

[42] Favaudon V, Caplier L, Monceau V, Pouzoulet F, Sayarath M, Fouillade C, et al. Ultrahigh dose-rate FLASH irradiation increases the differential response between normal and tumor tissue in mice. Science translational medicine. 2014;6:245ra93ra93.

[43] Montay-Gruel Pierre, Bouchet Audrey, Jaccard Maud, Patin David, Serduc Raphael, Aim Warren, Petersson Kristoffer, Petit Benoit, Bailat Claude, Bourhis Jean, Bräuer-Krisch Elke, Vozenin Marie-Catherine. X-rays can trigger the FLASH effect: Ultra-high dose-rate synchrotron light source prevents normal brain injury after whole brain irradiation in mice. Radiother Oncol 2018;129(3):582-8. https://doi.org/10.1016/j.radonc.2018.08.016.

[44] Bazalova-Carter Magdalena, Esplen Nolan. On the capabilities of conventional xray tubes to deliver ultra-high (FLASH) dose rates. Med. Phys. 2019;46(12): 5690-5. https://doi.org/10.1002/mp.13858.

[45] Lindfors Karen K, Boone John M, Nelson Thomas R, Yang Kai, Kwan Alexander LC, Miller DeWitt F. Dedicated Breast CT: Initial Clinical Experience. Radiology 2008; 246(3):725-33. https://doi.org/10.1148/radiol.2463070410.

[46] Prionas Nicolas D, McKenney Sarah E, Stern Robin L, Boone John M. Kilovoltage Rotational External Beam Radiotherapy on a Breast Computed Tomography Platform: A Feasibility Study. Int J Rad Oncol Biol Phys 2012;84(2):533-9. https:// doi.org/10.1016/j.ijrobp.2011.12.042.

[47] Buonanno F, Sarno A, De Lucia PA, Di Lillo F, Masi M, Di Franco F, Mettivier G, Russo $P$. Rotational radiotherapy of breast cancer with polyenergetic kilovoltage $X$ ray beams: An experimental and Monte Carlo phantom study. Phys Med 2019;62: 63-72. https://doi.org/10.1016/j.ejmp.2019.05.002.

[48] Di Lillo Francesca, Mettivier Giovanni, Sarno Antonio, Castriconi Roberta, Russo Paolo. Towards breast cancer rotational radiotherapy with synchrotron radiation. Phys Med 2017;41:20-5. https://doi.org/10.1016/j.ejmp.2017.06.009.

[49] Di Lillo F, Mettivier G, Castriconi R, Sarno A, Stevenson AW, Hall CJ, et al. Synchrotron radiation external beam rotational radiotherapy of breast cancer: proof of principle. Journal of synchrotron radiation. 2018;25:857-68.

[50] Bazalova-Carter Magdalena, Weil Michael D, Breitkreutz Dylan Yamabe, Wilfley Brian P, Graves Edward E. Feasibility of external beam radiation therapy to deep-seated targets with kilovoltage x-rays. Med Phys 2017;44(2):597-607. https://doi.org/10.1002/mp.12047.

[51] Breitkreutz Dylan Y, Weil Michael D, Zavgorodni Sergei, BazalovaCarter Magdalena. Monte Carlo simulations of a kilovoltage external beam radiotherapy system on phantoms and breast patients. Med Phys 2017;44(12) 6548-59. https://doi.org/10.1002/mp.12619.

[52] Breitkreutz Dylan Y, Renaud Marc-André, Seuntjens Jan, Weil Michael D, Zavgorodni Sergei, Bazalova-Carter Magdalena. Inverse optimization of low-cost kilovoltage x-ray arc therapy plans. Med Phys 2018;45(11):5161-71. https://doi. org $/ 10.1002 / \mathrm{mp} .13153$

[53] Breitkreutz DY, Renaud M-A, Weil MD, Zavgorodni S, Han J, Baxter H, et al. Monte Carlo calculated kilovoltage $\mathrm{x}$-ray arc therapy plans for three lung cancer patients. Biomedical Physics \& Engineering Express. 2019;5:065022.

[54] Stalbaum T, Boyd D, Weil M, Chen H, Plies M, Song S, et al. $200 \mathrm{kV}$ x-ray source for radiotherapy and imaging: preliminary results and discussion. Medical Imaging 2020: Physics of Medical Imaging: International Society for Optics and Photonics; 2020. p. 113123I.

[55] Zankowski C, Adelsheim C, Pyyry J, Kuusela E. Radiotherapy treatment planning using artificial intelligence (ai) engines. Google Patents; 2019.

[56] Sarno A, Mettivier G, Russo P, Drebot I, Petrillo V, Bacci A, et al. Kilovoltage rotational radiotherapy of breast cancer with the BriXS source. Journal of Instrumentation. 2020;15:C05012.

[57] Loughery B, Halford R, Dess K, Rakowski J, Cox M, Koh J, et al. A proof of concept kilovoltage intensity modulated radiotherapy platform for the treatment of glioblastoma multiforme. Biomedical Physics \& Engineering Express. 2019;5: 055013 .

[58] Bentzen Søren M, Constine Louis S, Deasy Joseph O, Eisbruch Avi, Jackson Andrew, Marks Lawrence B, Ten Haken Randall K, Yorke Ellen D. Quantitative Analyses of Normal Tissue Effects in the Clinic (QUANTEC): An Introduction to the Scientific Issues. Int J Rad Oncol Biol Phys 2010;76(3):S3-9. https://doi.org/10.1016/j.ijrobp.2009.09.040. 
[59] Icrp I. Publication 61: Annual limits on intake of radionuclides for workers based on the 1990 recommendations. New York: Pergamon Press; 1990.

[60] Amols HI, Lagueux B, Cagna D. Radiobiological Effectiveness (RBE) of Megavoltage X-Ray and Electron Beams in Radiotherapy. Radiat Res 1986;105(1):58. https:// doi.org/10.2307/3576725.

[61] Noone A, Howlader N, Krapcho M, Miller D, Brest A, Yu M, et al. SEER cancer statistics review, 1975-2015. Bethesda, MD: National Cancer Institute; 2018. p. 4.
[62] Sethi Anil, Emami Bahman, Small Jr William, Thomas Tarita. Intraoperative Radiotherapy With INTRABEAM: Technical and Dosimetric Considerations. Front Oncol 2018;8(74). https://doi.org/10.3389/fonc.2018.00074.

[63] Esplen Nolan, Mendonca Marc, Bazalova-Carter Magdalena. Physics and biology of ultrahigh dose-rate (FLASH) radiotherapy: a topical review. Phys Med Biol 2020. In press. 